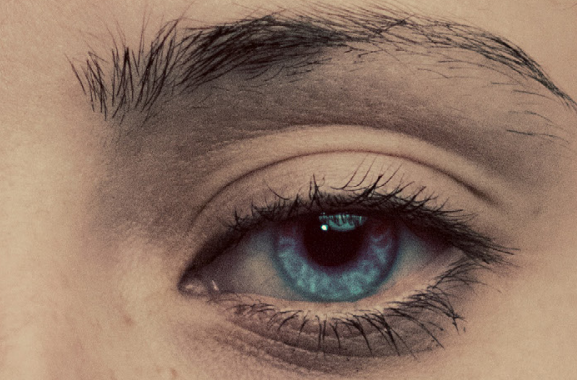

Artigo recebido em: 29/01/2017
Artigo aprovado em: 16/10/2017
Dol 10.5380/2238-0701.2017n14p309-329 
Poder. Território. Discurso midiático. 


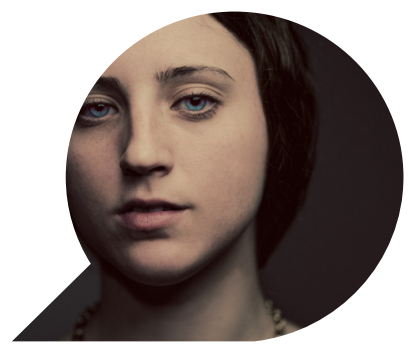

\title{
Poder, território e discurso: os suábios do Danúbio em Guarapuava-PR
}

\author{
Power, territory and speech: \\ the Danube Swabians in Guarapuava PR \\ Poder, territorio y discurso: \\ los Suabos de Danubio en Guarapuava PR
}

MÁRCIA DA SILVA*

\section{GILSON APARECIDO BOSCHIERO**}

Resumo: O objetivo deste texto é apresentar uma leitura, dentre diversas possíveis, sobre os imigrantes denominados/autonominados de Suábios do Danúbio, que ocuparam parte do território do município de Guarapuava, no Paraná, bem como analisar os discursos produzidos e reproduzidos historicamente pelos próprios Suábios, pela sociedade e pela mídia locais, que congregaram, aos mesmos, trunfos de poder, associando-os a ideia de desenvolvi-

\footnotetext{
* Doutora em Geografia pela Unesp de Presidente Prudente-SP. Professora da Universidade Estadual do Centro-Oeste (Unicentro), campus de Guarapuava-PR e membro do Grupo de Pesquisa Redes de Poder, Migrações e Dinâmicas Territoriais (Gepes). E-mail: <marcia.silvams@gmail.com>.

** Mestre em Geografia pela Unicentro/PR. Graduado em Jornalismo pela Unimep - Universidade Metodista de Piracicaba-SP. Professor da Universidade Estadual do Centro-Oeste (Unicentro), campus de Guarapuava-PR. E-mail: <gilsonboschiero@yahoo.com.br>.
} 
mento local/regional. Os Suábios do Danúbio são originários do Sudeste da Europa, nas proximidades do rio Danúbio, e saíram compulsoriamente de suas terras para viver em campos de refugiados, na Áustria, após a Segunda Guerra Mundial. Em decorrência, diversas famílias inscreveram-se em projetos que visavam a imigração para outros países, sendo este o caso de 500 destas que foram aceitas para a criação de uma cooperativa agrícola no Brasil, a partir de incentivos governamentais, daí fixando-se, neste país, no município de Guarapuava. As reflexões sobre os conceitos de poder e de território ajudam a explicar as características da ocupação realizada pelo grupo, com a fundação da Cooperativa Agrária e a construção de cinco colônias (ao longo dos anos 1950) que, mais tarde, tornaram-se oficialmente o distrito de Entre Rios, de características peculiares à arquitetura e a cultura germânicas. Como procedimentos metodológicos foram realizadas entrevistas, observações in loco e análise de jornal impresso e de site de notícias locais, que nos levaram a resultados significativos sobre parte da história e da relação com o território deste grupo.

Palavras-chave: Poder; Território; Discurso; Suábios do Danúbio.

Abstract: The purpose of this text is to present a reading, about the so - called Danubian Swabian immigrants, who occupied part of the territory of the city of Guarapuava, Paraná, as well as to analyze the discourses produced and reproduced historically by Swabians themselves, by local society and the media, which brought them together with the potential of being able to associate them with the idea of local / regional development. The Danubian Swabian originate from south-east Europe, near the Danube, and have compulsorily left their lands to live in refugee camps in Austria after World War II. As a result, several families enrolled in projects that aimed at immigration to other countries, case of 500 of these that were accepted for the creation of an agricultural cooperative in Brazil, from governmental incentives, hence setting in this Country, in the city of Guarapuava. Reflections on the concepts of power and territory helps to explain the characteristics of the occupation carried out by the group, the founding of the Agrarian Cooperative and the construction of five colonies (during the 1950s), which later would became officially the District of Entre Rios, with peculiar characteristics from the German architecture and culture. Methodological procedures included interviews, on-site observations and analysis of printed newspapers and local news sites, which led to significant results on part of the history and the relationship with the territory of this group. 
Keywords: Power; Territory; Discurse; Danubian Swabian.

Resumen: El objetivo de este texto es presentar una lectura sobre los inmigrantes autonominados de Suábios de lo Danúbio, que ocuparam parte del territorio del municipio de Guarapuava, no Paraná, así como el análisis de los discursos producidos y reproducidos históricamente por los propios Suábios, por la sociedad y por los medios de comunicación locales, que congregaron, a los mismos, los trunfos de poder, asociando-os una ideia de desarrollo local / regional. Los Suábios de lo Danúbio son originarios del Sudeste de Europa, en las proximidades del río Danúbio, y son obligatorios de sus terrenos para vivir en campos de refugiados, en Austria, después de Segunda Guerra Mundial. En consecuencia, diversas familias se inscribieron en proyectos destinados a la inmigración a otros países, siendo éste el caso de 500 de las que fueron aceptadas para la creación de una cooperativa agrícola en Brasil, a partir de incentivos gubernamentales, de ahí fijándose, en este, En el municipio de Guarapuava. Las reflexiones sobre los conceptos de poder y de territorio ayudan a explicar las características de la ocupación realizada por el grupo, con la fundación de la Cooperativa Agraria y la construcción de cinco colonias (a lo largo de los años 1950) que más tarde se convirtieron oficialmente Distrito de Entre Ríos, de características peculiares a la arquitectura y la cultura germánicas. Como procedimientos metodológicos se realizaron entrevistas, observaciones in situ y análisis de prensa impresa y de sitio de noticias locales, que nos llevaron a resultados significativos sobre parte de la historia y de la relación con el territorio de este grupo.

Palabras clave: Poder; Território; Discurso; Suábios do Danubio. 


\section{Introdução}

O processo que compreende a dinâmica de chegada e adaptação, nas últimas seis décadas, dos imigrantes suábios do Danúbio a Guarapuava/ $\mathrm{PR}$ não foi simples devido às complexidades histórica e cultural. Isso porque os suábios do Danúbio são oriundos das guerras austro-húngaras e turcas ocorridas entre 1683 e 1718. Em 1720, os suábios partiram da cidade de Ulm, na Suábia (região do estado Baden Württemberg, sul da atual Alemanha), e depois de quase dois meses de viagem pelo rio Danúbio chegaram às planícies férteis (partes da atual Hungria, Romênia e Croácia) (COOPERATIVA AGRÁRIA, 2014).

As terras consideradas produtivas foram repovoadas com colonizações de germânicos (suábios), austríacos e húngaros e "após gerações de muito trabalho, a região do médio Rio Danúbio tornou-se o celeiro do Império Austro-Húngaro e pátria dos suábios do Danúbio" (COOPERATIVA AGRÁRIA, 2014).

Após a I Guerra Mundial, o território foi dividido entre a Romênia, a Iugoslávia e a Hungria e os suábios do Danúbio tornaram-se estrangeiros na própria pátria (COOPERATIVA AGRÁRIA, 2014). Mas, em 1943, a ascensão do movimento comunista Partisan, que se opunha ao atual regime, começa na Iugoslávia um processo de limpeza étnica da população alemã e, como afirma Friedrich (2005), jovens suábios integraram o exército alemão compulsoriamente ou por saberem o idioma e acenderam a rivalidade entre os povos nativos.

As atrocidades cometidas pela ganância Alemã sob o comando de Hitler, e sendo eles descendentes dos alemães, fizeram dos suábios da Iugoslávia as primeiras vítimas do ódio comunista dessa guerra. Calculase que 200.000 mil suábios morreram, na sua maioria mulheres, velhos e crianças (FRIEDRICH, 2005, p. 44).

Descendentes de alemães e suábios foram expulsos de suas terras, abandonando suas casas, fazendas e equipamentos. "Com o avanço das tropas comunistas na II Guerra Mundial, eles tiveram que fugir. Foram expulsos e muitos morreram durante e após a guerra" (COOPERATIVA AGRÁRIA, 2014). Uma multidão de desalojados, entre eles os suábios (ELFES, 1971), refugiaram-se na Áustria, que ofereceu asilo e onde permaneceram por sete anos em condições precárias, como afirma Gärtner (2009). 
Não havia trabalho nem mantimentos suficientes. Foi então que o governo suíço, de longa tradição humanitária, começou a agir. Terminada a guerra os refugiados poderiam finalmente prosseguir a sua migração para outros países da Europa ou para além-mar (GÄRTNER, 2009, p. 1.077).

Como os suábios eram agricultores, a instituição humanitária “Ajuda Suíça para a Europa" (Schweizer Europa-Hilfe) idealizou um projeto de cooperativa agrícola em outro país, como alternativa de vida para esse grupo que estava na Áustria. 500 famílias (2.446 pessoas) se inscreveram para o projeto que criaria uma cooperativa agrícola no Brasil. Após rejeitarem algumas propostas de outros estados brasileiros interessados na vinda desses imigrantes, a partir de 1951, os suábios do Danúbio se estabeleceram em Guarapuava, data da instalação da Colônia de Entre Rios, conforme Mapa 1.

Mapa 1: Localização do estado do Paraná, do município de Guarapuava e do distrito de Entre Rios formado pelas 5 colônias.
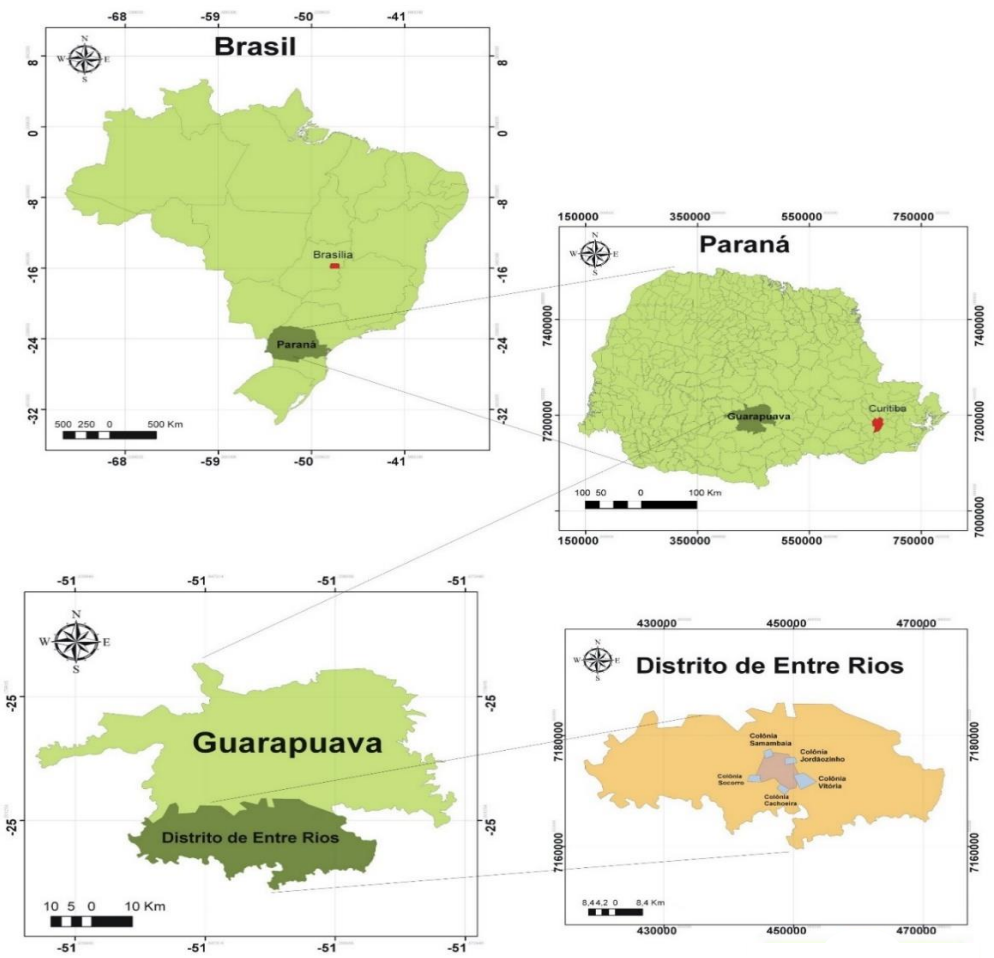

Fonte: O autor, adaptação de Atlas Geográfico (IBGE 2004). 
Ao analisarmos a colonização do distrito de Entre Rios, podemos dizer que se iniciou aí um processo de demarcação de territórios, com ações políticas, econômicas e sociais. Desta forma, os conceitos de poder, território ajudam a explicar as características de ocupação dos suábios no distrito de Entre Rios, em Guarapuava, no Paraná, como também fazer a leitura deste grupo a partir dos diversos discursos produzidos e reproduzidos historicamente pelos próprios suábios, pela sociedade e pela mídia locais.

\section{Poder, território e o papel dos Suábios do Danúbio na economia de Guarapuava-PR}

De acordo com Haesbaert (2004), são várias as formas expressas pelas territorialidades, como a política, econômica e cultural. Saquet $(2004 ; 2007)$ indica concordar com a abordagem defendida por Haesbaert e utiliza Raffestin (1993) para incluir um elemento a mais para o conceito de território, que é a manifestação e o exercício do poder, presente nas relações sociais.

Do mesmo modo, Souza (2000) acredita que o território é um espaço definido e marcado pelas relações de poder e, portanto, é também um instrumento de exercício de poder, com dominantes e dominados, um espaço com caráter essencialmente político, onde as relações de poder definem o território. Raffestin (1993) traz para o conceito de território o caráter político, diferenciando-o de espaço, onde o primeiro se apoia no segundo, mas não pode ser confundido com ele.

Essas diferentes relações de poder sobre o território alteraram a posse e o uso da terra com as ações promovidas pelos sujeitos que estão assentados neste espaço. Desta forma, de acordo com Raffestin (1993) é impossível falar de território sem levarmos em consideração as ações de poder (ou de poderes) que nele incidem. E aí existem várias formas de se expressar o poder, que pode ser de um governante ou de um grupo estabelecido, a manutenção da língua, o exercício de uma crença religiosa, a defesa de uma posição política e a exploração dos recursos naturais. Mais que isso, para Raffestin (1993), o poder está presente em todo o tipo de relação social.

O território, neste contexto, deve ser tratado com todas as complexidades produzidas pelas relações sociais submersas num campo de forças imposto pela produção capitalista. A chegada desses imigrantes traria prosperidade para a região, com a implantação da agricultura de 
cereais em uma terra sem uso produtivo. De acordo com Stein (2011), as terras escolhidas pelos imigrantes foram desapropriadas pelo governo do Paraná, já que serviam para criação de animais e para o cultivo de culturas de subsistência (STEIN, 2011, p. 61).

A partir dessa reocupação, as áreas passaram a ser cultivadas com lavouras de trigo, transformando aquele espaço geográfico, criando um novo território agora formado por cinco colônias que mantém, a partir da transformação do território, as marcas do local, da tradição e da identidade de origem.

Neste sentido é que os conceitos de poder (e, na prática, dos grupos de poder) e de território ajudam explicar as características de ocupação dos suábios do Danúbio no distrito de Entre Rios no contexto da exterioridade, ou seja, da reprodução social e cultural alemãs. Isso se explica de formas diversas na Geografia. Para Ratzel ${ }^{1}$ (apud SOUZA, 2000), o território tem vinculação com o boden (solo) e o patriotismo, que encontrava sua identidade no Estado-Nação. Souza (2000) acredita que o território é um espaço definido e marcado pelas relações de poder e, portanto, é também um instrumento de exercício de poder, com dominantes e dominados.

Raffestin (1993) traz para o conceito de território o caráter político, diferenciando-o de espaço. Desta forma, de acordo com o autor, não é possível falar de território sem levarmos em consideração as ações de poder que nele incidem como a manutenção da língua, das tradições, das crenças, em especial a religiosa.

A criação da Cooperativa Agrária por este grupo de imigrantes ou por parte dele, em Entre Rios, possibilitou a reorganização do território e da economia local a partir, principalmente, do setor do agronegócio e da arrecadação de impostos.

Para avaliarmos a intensidade de seus negócios e os reflexos positivos para a economia e, em tese, para o desenvolvimento local/regional a partir de Guarapuava, recorremos a uma análise de dados socioeconômicos sobre o município, tendo como fonte o Instituto Brasileiro de Geografia e Estatística (IBGE, 2010). Na tabela 1 é possível observar os domicílios particulares permanentes, com rendimentos familiar e domiciliar e o valor do rendimento nominal médio mensal, para o qual verifica-se discrepâncias no valor do rendimento entre todos os distritos

\footnotetext{
${ }^{1}$ RATZEL, Friedrich (1844 - 1904) foi um geógrafo e etnólogo alemão, nascido em Karlsruhe e criador da antropogeografia ou Geografia Humana. Seus estudos sobre o tema das relações entre espaço e poder deram origem à Geografia Política.
} 
do município de Guarapuava se comparados com o distrito de Entre Rios.

Tabela 1: Guarapuava: Domicílios particulares permanentes, total e com rendimento domiciliar, valor do rendimento nominal médio mensal, total e com rendimento domiciliar, por situação do domicílio e classes de rendimento nominal mensal domiciliar.

\begin{tabular}{|c|c|c|c|c|c|c|}
\hline \multirow[b]{2}{*}{$\begin{array}{l}\text { Municipio e } \\
\text { Distrito }\end{array}$} & \multicolumn{6}{|c|}{ Variável } \\
\hline & $\begin{array}{l}\text { Domicilios } \\
\text { particulares } \\
\text { permanestes } \\
\text { (Unidades) }\end{array}$ & $\begin{array}{c}\text { Domicilios } \\
\text { particulares } \\
\text { permanentes } \\
\text { (Percentual) }\end{array}$ & $\begin{array}{l}\text { Domicilios } \\
\text { particulares } \\
\text { permanentes } \\
\text { com rendimento } \\
\text { familiar } \\
\text { (Unidades) }\end{array}$ & $\begin{array}{l}\text { Domicilios } \\
\text { particulares } \\
\text { permanentes } \\
\text { com } \\
\text { rendimento } \\
\text { familiar } \\
\text { (Percentual) }\end{array}$ & $\begin{array}{c}\text { Valor do } \\
\text { rendimento médio } \\
\text { mensal dos } \\
\text { domicílios } \\
\text { particulares } \\
\text { permanentes } \\
\text { (Reais) }\end{array}$ & $\begin{array}{l}\text { Valor do rendimento } \\
\text { médio mensal dos } \\
\text { domicílios } \\
\text { particulares } \\
\text { permanentes com } \\
\text { rendimento domiciliar } \\
\text { (Reais) }\end{array}$ \\
\hline Guarapuava - PR & 50.553 & 100,00 & 49.479 & 100,00 & $2.051,31$ & $2.095,83$ \\
\hline $\begin{array}{l}\text { Atalaia - } \\
\text { Guarapuava - PR }\end{array}$ & 93 & 100,00 & 91 & 100,00 & $1.552,32$ & $1.586,44$ \\
\hline Entre Rios - & & & & & & \\
\hline Guarapuava - PR & 3.111 & 100,00 & 3.037 & 100,00 & $2.429,80$ & $2.489,01$ \\
\hline $\begin{array}{l}\text { Guairacá - } \\
\text { Guarapuava - PR }\end{array}$ & 510 & 100,00 & 488 & 100,00 & 863,11 & 902,02 \\
\hline Guará - & & & & & & \\
\hline Guarapuava - PR & 1.090 & 100,00 & 1.051 & 100,00 & 958,36 & 993,92 \\
\hline $\begin{array}{l}\text { Palmeirinha - } \\
\text { Guarapuava - PR }\end{array}$ & 1.252 & 100,00 & 1.210 & 100,00 & $1.072,67$ & $1.109,91$ \\
\hline
\end{tabular}

Fonte: IBGE (2010).

Se compararmos o valor do rendimento médio mensal dos domicílios particulares permanentes é possível observar que o valor médio mensal de rendimento domiciliar no distrito de Entre Rios é de R\$ $2.429,80,18,45 \%$ superior à média na sede do município de Guarapuava, que tem o valor de $\mathrm{R} \$ 2.051,31$. A distribuição de renda e o consequente desenvolvimento socioeconômico e cultural é desigual em Guarapuava, mesmo com a presença de algumas empresas importantes economicamente, como a Cooperativa Agrária, demonstrando que a distribuição de renda passa longe de ser razoavelmente equânime.

O presidente da Cooperativa Agrária, $\operatorname{Karl}^{2}$ (2013) fez uma análise sobre a riqueza gerada pela Cooperativa Agrária e sua contribuição para o desenvolvimento local e regional.

\footnotetext{
2 Entrevista com Jorge Karl, concedida a Gilson Boschiero, na sede administrativa da Cooperativa Agrária, no distrito de Entre Rios no dia 31/05/2013. Jorge Karl é cooperado desde os anos 1980 e assumiu a presidência em março de 1999, cargo que ocupa até os dias atuais.
} 
Se você pegar o PIB do município do norte do Paraná e pegar o PIB de Guarapuava ou o PIB de municípios semelhantes em termos de extensão territorial e população, você vai ver que o PIB lá é muito maior. Por quê? Porque lá tem mais Agrária, tem mais empresas que geram riquezas. E aqui são poucas, a Agrária é uma delas. E a outra questão também é a natureza do negócio. (KARL, 2013).

Várias são as teorias que tentam explicar o desenvolvimento ou atraso econômico de uma região. Segundo Oliveira (2007), pela Teoria da Causação Circular Cumulativa, de Myrdal (1982):

[...] as atividades que trazem muita lucratividade tendem a concentrar-se em determinadas regiões ricas, deixando a margem regiões mais pobres do país. As regiões menos favorecidas entram por sua vez em um processo acumulativo regressivo, com saída de imigrantes e diminuição da demanda interna, gerando uma redução de investimento. (OLIVEIRA, 2007, p. 6).

Ou seja, a concentração de riquezas baseia-se em vantagens de competição pré-estabelecidas pelo mercado e, desta forma, uma região ou um município caracterizado por grandes diferenças de renda está em desvantagem na corrida pelo crescimento econômico.

Se a concentração de riquezas é resultado de um processo competitivo, supomos que o desenvolvimento econômico não ocorre de maneira uniforme, já que segue características regionais que apresentam potencial para investimento, e podem resultar em desenvolvimento ou estagnação de uma região (MYRDAL, 1982).

\section{Os Suábios do Danúbio: o discurso e a realidade}

O movimento migratório para o município de Guarapuava trouxe costumes e culturas diferentes, desenvolvimento local/regional, mas também segregação e exclusão. É na representação cultural e na identidade do grupo pesquisado que encontramos os significados das práticas que estabelecem os laços sociais, tanto para a cooperação quanto para a exclusão, por meio de discursos ou da própria realidade.

A realidade está posta, mas pode ser lida e apreendida de diversas formas. Aqui, optou-se por averiguá-la, além de outros, pelos discursos produzidos. Assim, a partir de observações de campo (na colônia de 
Entre Rios), de entrevistas (com sujeitos participantes deste processo de reterritorialização) e de pesquisas na mídia local (Jornal Diário de Guarapuava e site Rede Sul de Notícias ${ }^{3}$ ) fizemos uma análise das conexões presentes no território a partir das relações de poder (econômico, político, cultural, ideológico) enquanto discurso e enquanto realidade.

Assim, destacamos os resultados alcançados por meio destes procedimentos metodológicos, os quais foram importantes para a compreensão das relações de apropriação do discurso e da realidade a partir do exógeno do endógeno aos suábios do Danúbio. O conceito de discurso é tomado pelo seu significado mais peculiar, qual seja, o de que este estaria fundamentado na afirmação que tem como regra aquilo que está oculto (SAUSSURRE, 2009).

Tendo esta afirmação como ponto inicial, é possível apreender que todo o discurso é um discurso de poder, na medida em que este tem por objetivo impor verdades a partir de dois aspectos, o de mascarar suas relações de poder, tornando-as menos visíveis e o de demonstrar sua luta pelo poder, destacando-o. Ambos, no entanto, buscam a desconstrução um do outro.

No âmbito da temática apresentada, compreende-se também o discurso como saberes, ideológicos ou não, que ordenam, organizam e definem o território. Assim, de acordo com Souza (2000, p. 7):

Os discursos [...] atravessam os lugares e dão visibilidade aos processos sociais, políticos, históricos e ideologicamente construídos. É desta perspectiva que o discurso produz uma ordenação e comportamentos também ordenados que levam a diferentes formas de controle que são organizadores de espaços.

Portanto, pensar aqui os vínculos entre território e discurso significa qualificá-los numa relação dialética em que ambos se fazem e são interdependentes, isto é, "o espaço não é neutro, mas socialmente produzido” (SOUZA, 2000, p. 4), apropriado como território.

A análise do discurso considera os processos e as condições de produção dos enunciados, os sujeitos que falam e as situações em que é produzido, como no proposto da realidade apropriada pelos suábios do Danúbio. Assim, nos parece correto que um discurso só pode ser analisado como expressão do imaginário social de seu produtor e, portanto, só pode ser apreendido quando referido às condições sociais de sua

\footnotetext{
${ }^{3}$ Também pela inexistência de outro periódico jornalístico diário impresso.
} 
produção. Esse encaminhamento pressupõe que em toda a sociedade a produção do discurso é controlada, selecionada, instituída pelos sujeitos que buscam revelar, classificar, ordenar, instituir o real.

O discurso, então, se articula com a estrutura socioeconômica sendo parte do próprio processo através do qual a sociedade se forma enquanto comunidade política, social e econômica.

Os discursos não são produzidos num vácuo. $\mathrm{O}$ discurso expressa $\mathrm{o}$ modo como está organizada a sociedade. A forma como os homens se relacionam, as relações sociais, as práticas sociais fazem juntas o 'tecido' da sociedade e o discurso é o resultado da representação do entendimento do homem acerca dessa organização social (SOUZA, 2000, p. 9).

O discurso ideológico busca, quase que frequentemente, construir uma imagem de território/região na qual há plena igualdade de condições, onde não há distinção entre ricos e pobres, mesmo que este apresente nível elevado de desigualdades, tanto econômicas, como sociopolíticas, como no caso do município de Guarapuava.

O discurso, assim, tem a capacidade de sedimentar e elaborar uma identidade territorial a partir de imagens enunciadas de acordo com os interesses de quem as produz. Como afirma Dundes (2007, p. 38):

Trata-se, portanto, de entender o discurso como um recurso, que através da produção ou acionamento de sentidos, constrói, diminui ou amplia "fronteiras" e reforça identidades regionais capazes de legitimar, criar e recriar, fazer ou refazer, ao menos ao nível das representações, uma região.

Portanto, se o discurso, compreende-se, é derivado do contexto e é produto de relações sociais, podendo ser revelador da relação sociedade $\mathrm{x}$ território. Como já argumentado, a construção de territórios remete-se a relações de poder e, consequentemente, o discurso se apresenta como uma das principais formas de manter essa relação.

Neste sentido, pode-se identificar, a partir da reportagem publicada no dia 5 de maio de 2011, pelo site Rede Sul de Notícias, sob o título: "Agrária comemora 60 anos de conquistas nesta quinta-feira", que o discurso midiático reforça a ideia de que os imigrantes suábios souberam reverter as dificuldades encontradas no cultivo da terra, com a modernização da agricultura, conforme trecho a seguir: 
Esta quinta-feira (5) marca os 60 anos de criação da Cooperativa Agrária, localizada no distrito de Entre Rios, em Guarapuava. Relembrar a história da cooperativa é traçar um percurso escrito com trabalho, suor e sucesso [...] como destaca a assessoria de comunicação da entidade (REDE SUL DE NOTÍCIAS, 05/05/2011).

Por outro aspecto, o de quem chegou e se apropriou do território de diversas formas, nos afirma Elke Leh $\mathrm{Basso}^{4}$ (2013) que a postura conservadora está nos guarapuavanos, que "não conseguiram abrir as fronteiras para novas culturas ou novos investimentos". Karin Katharina Leh $^{5}$ (2013), também integrante do grupo suábio, afirma que esse conservadorismo é cultural. "Nós aqui temos muitas coisas culturais na nossa comunidade, mas Guarapuava tem essa cultura fechada, acho que muito mais impregnada que os próprios alemães aqui”.

Outro fator cultural que expressa poder é a língua mantida pelos pioneiros e descendentes. Sobre a língua, Leh (2013) afirmou: "Nós falamos entre nós o alemão [...] Nós somos brasileiras, só continuamos sendo diferentes por causa dessa tradição." E essa diferença estaria presente ainda pela cultura. Apesar dessa constatação que valoriza a cultura do diferente e que a coloca como singular ao grupo, Silvestri Filho ${ }^{6}$ (2013) faz uma análise positiva e de contribuição cultural dos suábios do Danúbio em Guarapuava:

Hoje em Guarapuava eu tenho uma festa tradicional no período de maio, que é a festa da Árvore de Maio. É deles, faz parte do calendário cultural do município. Então eles enriquecem a nossa cultura, preservando a própria cultura deles (SILVESTRI FILHO, 2013).

O site Rede Sul de Notícias do dia 12/10/2012 tratou da Festa da Cevada celebrada todo ano para comemorar as colheitas com o título: "Peixada movimenta a programação da Festa da Cevada neste sábado". A reportagem apresenta a festa com vários adjetivos: tradicional, famosa e grande, e traz em partes do texto uma dimensão do que é o evento.

\footnotetext{
${ }^{4}$ Entrevista com Elke Leh Basso, concedida a Gilson Boschiero, no Memorial Mathias e Elizabeth Leh, no distrito de Entre Rios no dia 28/05/2013. Basso é filha de Mathias Leh que foi presidente da Cooperativa Agrária por 28 anos.

${ }^{5}$ Entrevista com Karin Katharina Leh, concedida a Gilson Boschiero, no Memorial Mathias e Elizabeth Leh, no distrito de Entre Rios no dia 28/05/2013. Leh é filha de Mathias Leh que foi presidente da Cooperativa Agrária por 28 anos.

${ }^{6}$ Entrevista com Cesar Silvestri Filho, prefeito de Guarapuava.
} 
Milhares de pessoas devem participar do baile, que acontece também nesse sábado (13). Segundo os organizadores do baile, tudo já está preparado [...] Estimativas garantem que devem ser servidos cerca de 5.000 peixes e mais de 4.000 litros de chope, nos dois dias de baile. (REDE SUL DE NOTÍCIAS, 12/10/2012).

A cobertura pela imprensa também ajuda na manutenção desse símbolo cultural ao noticiar as festividades mensurando a quantidade de pessoas esperadas para o baile e a quantidade de peixes e de chopp que devem ser servidos. $\mathrm{O}$ exemplo mais recente de preocupação com a manutenção dessa cultura é a cooperação com a Alemanha em um acordo de bilateral entre Guarapuava e Rastatt, cidade alemã que há 25 anos se tornou coirmã. Rastatt está localizada no Sul da Alemanha, no estado de Baden-Württemberg (Mapa 2) e tem aproximadamente 48 mil habitantes.

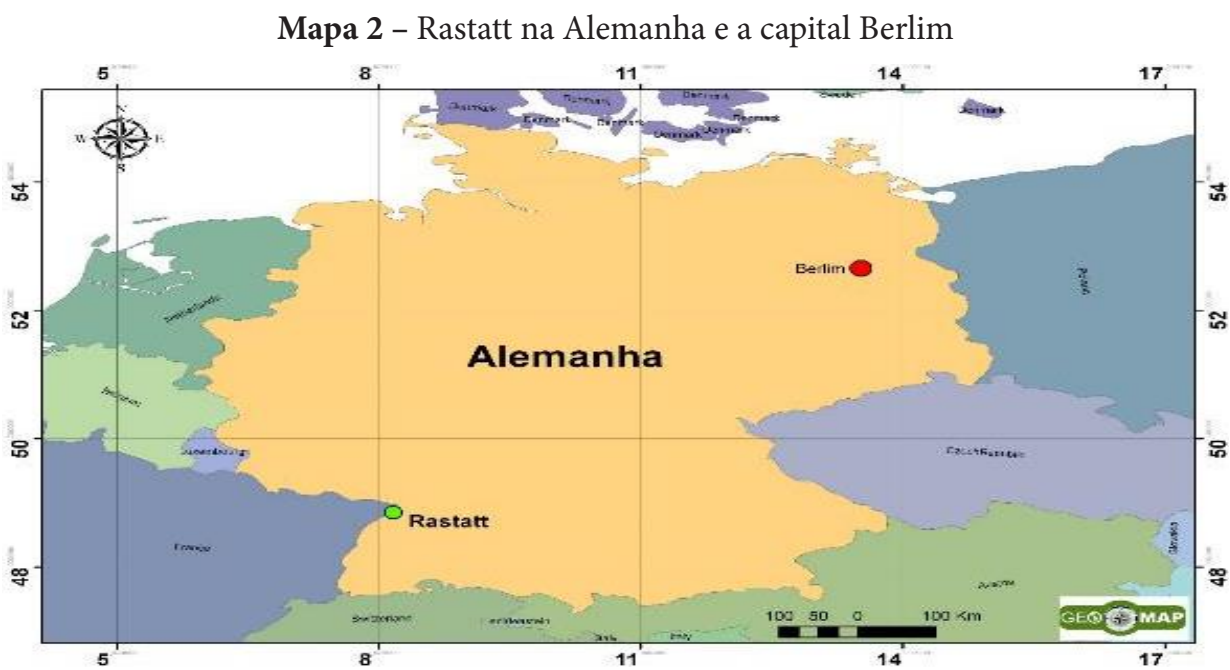

Fonte: o autor, adaptação GeoMap.

O prefeito de Rastatt, Hans Jürgen Pütsch ${ }^{7}$ participou das comemorações da Festa da Cevada no distrito de Entre Rios em outubro de 2013. Perguntado sobre a cooperação econômica entre os dois municípios e a vinda de empresas para Guarapuava, Pütsch (2013) disse que o foco da assinatura feita há 25 anos é a troca cultural, não havendo nenhum intercâmbio econômico, empresarial ou científico (PÜTSCH, 2013).

\footnotetext{
${ }^{7}$ Entrevista com Hans Jürgen Pütsch, prefeito há 6 anos de Rastatt concedida a Gilson Boschiero, no distrito de Entre Rios no dia 13/10/2013.
} 
Mas em reportagem postada no portal de imprensa da Cooperativa Agrária, no entanto, o discurso é outro. No dia 10/10/2013 o portal publicou uma reportagem com o título: "Delegação de Rastatt visita coirmã e participa da Festa da Cevada 2013" e informa que o acordo firmado em 1988 tem por objetivo "estreitar o relacionamento entre ambas as cidades, assim como entre Rastatt e o distrito de Entre Rios, no sentido de fomentar o intercâmbio cultural, econômico e científico".

Outra reportagem sobre o tema foi publicada pelo Diário de Guarapuava no dia 11/10/2013 com o título: "Intercâmbio busca compreensão entre os povos, diz prefeito de Rastatt" e com subtítulo: "Para Hans Pütsch, as recentes visitas entre Guarapuava e a cidade alemã de Rastatt significam um novo momento, em que o intercâmbio deixa de ser apenas cultural, e se torna também econômico". Foi exatamente esse enfoque que o prefeito alemão negou durante a nossa entrevista.

O que merece ser evidenciado através destas leituras do discurso midiático (e de certa forma da própria realidade representada ideologicamente) e é o fato de existir uma pauta de supervalorização desses imigrantes por parte da mídia local, de algumas representações políticas e dos próprios suábios, o que também reforça a identidade, a cultura e, por consequência, confere-lhes poder.

O poder é um conceito de difícil análise e, para o grupo aqui estudado, pode ser originário de diversas instituições que colaboraram/ colaboram para o desenvolvimento/consolidação do mesmo, como o Estado, os governos, lideranças político-partidárias locais e regionais, grupos específicos (os empresários, os latifundiários, os proprietários dos meios de comunicação entre outros) que se beneficiam do papel dos mesmos, de outros grupos de poder, bem como no interior de um grupo determinado.

Podemos falar, então, em vários poderes disputando territórios e interesses opostos, como no caso dos suábios do Danúbio, o que nos faz acreditar que um território está em constante disputa por diversos grupos de poder. Se partirmos do conceito de Poulantzas (2000, p. 149) temos que "a capacidade de uma classe em realizar seus interesses está em oposição à capacidade (e interesse) de outras classes: o poder é, assim, estritamente relacional", e está atrelado às relações sociais que se dão em um território num determinado tempo e espaço e é marcado por diferenças e conflitos.

Assim, enquanto o conservadorismo político-econômico dificultou o desenvolvimento de Guarapuava, a manutenção da cultura dos suábios fortaleceu o grupo conferindo-lhes poder (em suas diversas 
nuances), reconhecimento social, mas também indícios de segregação, induzida ou escolhida, que pode ser imposta por uma pessoa ou grupo social e pode ter o objetivo de isolar, de afastar e de evitar contato social com o "diferente".

Assim, o segregado (ou aquele que se auto segrega) é isolado, colocado à margem de uma comunidade estabelecida, isto é, em exclusão. Wanderley (2001) faz uma reflexão acerca do conceito de exclusão e de suas causas, que podem ser explicadas por modelos e pelas estruturas econômicas que elevam as desigualdades na qualidade de vida da população.

Os excluídos não são simplesmente rejeitados física, geográfica ou materialmente, não apenas do mercado e de suas trocas, mas de todas as riquezas espirituais, seus valores não são reconhecidos, ou seja, há também uma exclusão cultural (WANDERLEY, 2001, p. 17 e 18).

O que a autora explica é que a exclusão/segregação não precisa ser necessariamente material, mas que pode ser subjetiva, a partir de crenças e costumes vividos diariamente por uma pessoa ou grupo social. Sawaia (2001) aborda a exclusão social sob a perspectiva ético-psicossociológica e integrante do processo histórico que inclui todas as esferas da vida social, do indivíduo, seus sentimentos e suas ações.

A sociedade exclui para incluir e esta transmutação, é condição da ordem social desigual, o que implica o caráter ilusório da inclusão. Todos estamos inseridos de algum modo, nem sempre decente e digno, no circuito reprodutivo das atividades econômicas, sendo a grande maioria da humanidade inserida através da insuficiência e das privações, que se desdobram para fora do econômico (SAWAIA, 2001, p. 8).

Sawaia (1995, p. 21) afirma que o conceito de segregação acaba encobrindo "a teia de relações e significações que dão vida aos espaços e, consequentemente, à ambiguidade que os caracteriza”. Neste sentido, o conceito de segregação é mais amplo que o de exclusão, por ir além da divisão geográfica que impõe limites a um lugar, tornando-o aparentemente isolado ou excluído. "A cidade compreende os espaços de intimidade cotidiana, onde se dão as relações mais personalizadas e onde se partilham carências - lugares onde a exposição do eu se dá sem perda do sentido" (SAWAIA, 1995, p. 22).

Não há como negar o significativo papel desempenho pelos suábios por meio de sua Cooperativa, que exerce importante função econômica 
para o município de Guarapuava, tanto pela geração de empregos quanto pela arrecadação de impostos. Por outro lado, há discursos, como alguns citados ao longo deste texto, que evidenciam aspectos de que essa contribuição não foi suficiente para o desenvolvimento do município e da região como um todo, mas sim que serviu como amparo exclusivo a estes imigrantes e seus descendentes.

Fatores como o conservadorismo político-econômico, setorização do agronegócio, ausência de outras indústrias com capacidade de geração de empregos e impostos, concentração de terras, infraestrutura e cultura ainda dificultam a inserção das benesses econômicas deste grupo de poder para o desenvolvimento mais amplo, já que também tiram proveito da apropriação histórica do território.

Apesar desta constatação, o discurso que amplifica a cooperação econômica e cultural por parte dos suábios como indutores do desenvolvimento de Guarapuava busca, ao mesmo tempo, eliminar ou minimizar os efeitos de um processo de segregação que envolveu imigrantes e moradores locais desde a chegada desses europeus ao município.

\section{Considerações finais}

$\mathrm{Na}$ relação poder, território e discurso apresentada a partir da investigação sobre o grupo de imigrantes denominados de suábios do Danúbio, estabelecidos no Distrito de Entre Rios, em Guarapuava, no Paraná, pode-se ressaltar algumas considerações para este artigo, sendo muitas outras possíveis a partir da pesquisa realizada. A história percorre caminhos que não só os oficiais divulgados pela Cooperativa Agrária e por representantes políticos e está presente no discurso das famílias dos descendentes.

Mais que isso, por meio da análise de dados econômicos, de reportagens publicadas e no conteúdo das entrevistas coletadas, percebemos que existe um esforço constante pela manutenção da história e da identidade cultural acerca dos suábios do Danúbio em Guarapuava, conferindo-lhes um status social diferenciado, e por consequência poder.

O discurso ideológico busca construir uma imagem na qual não existe diferenças entre ricos e pobres, mesmo que este apresente nível elevado de desigualdades econômicas e sociopolíticas. Assim, pretende-se fortalecer uma identidade territorial de acordo com os interesses de quem as produz. Observamos também que existe uma supervalorização desses imigrantes, o que é reforçado por parte da mídia local, 
de algumas representações políticas e dos próprios suábios. Enquanto o conservadorismo político-econômico dificultou o desenvolvimento de Guarapuava, a manutenção da cultura destes imigrantes fortaleceu o grupo conferindo-lhes poder e também indícios de segregação.

Reforça-se o discurso de que este grupo trouxe progresso econômico, social e cultural para o município, com a uma nova forma de ocupação do solo. Mas percebe-se essa organização do trabalho e da cultura, estão primeiramente voltados ao bem-estar do grupo, e não existe homogeneidade da divisão de renda em todos os distritos do município.

Assim, o assentamento desses imigrantes ao longo de seis décadas acabou dando origem a outro território, a colônia dos alemães, resultado de um processo de segregação espacial e cultural que valorizou, em primeiro lugar, tradição e cultura germânicas.

\section{REFERÊNCIAS}

BASSO, Elke L. Entrevista concedida a Gilson Boschiero. Entre Rios/Guarapuava, Memorial Mathias e Elizabeth Leh, 25 mai. 2013.

COOPERATIVA AGRÁRIA. Informativo Agrária. Disponível em: <http://www. agraria.com.br/ex tranet/arquivos/portal_informativo/2012_12.pdf >. Acesso em: 28 out. 2013.

COOPERATIVA AGRÁRIA. Perfil 2014. Enviado por e-mail pela Assessoria de Imprensa da cooperativa para este pesquisador no dia 16 jan. 2014.

\section{DIÁRIO DE GUARAPUAVA. Celebração ecumênica abre Festa da Cevada}

2012. Guarapuava, 10 out. 2012. Disponível em: $<$ http://www.diariodeguarapuava. com.br/notícias/g uarapuava/11,5419,10,10,celebracao-ecumenica-abre-festa-dacevada-2012.shtml>. Acesso em: 16 jun. 2013.

DUNDES, Ana Cláudia. Região do devir e região do atraso. Discurso e representações sobre a região de Presidente Prudente- SP. São Paulo: UNESP, 2007. (Tese de Doutorado).

ELFES, Albert. Suábios no Paraná. Curitiba: [s.n.], 1971. FRIEDRICH, Marli. Gênese e evolução do distrito de Entre Rios e a Cooperativa Agrária. Monografia apresentada no Curso de Pós-Graduação em Geografia da Unicentro, 2005.

GÄRTNER, Monique. História, memória e identidade: considerações acerca da ocupação da região de Entre Rios feita pelos suábios do Danúbio no Paraná (1951- 
1971). In: Congresso Internacional de História. Maringá/PR. Agosto/2009. Disponível em: <http://www.pph.uem.br/cih/anais/trabalhos/70.pdf>. Acesso em: 12 de out. 2013.

HAESBAERT, Rogério. O Mito da desterritorialização - Do “Fim dos Territórios” à Multiterritorialidade. Rio de Janeiro: Bertrand Brasil, 2004.

IBGE - Instituto Brasileiro de Geografia e Estatística. Disponível em: <http://www. ibge.

gov .br/home/estatistica/populacao/censo2010/>. Acesso em: 18 fev. 2013.

KARL, Jorge. Entrevista concedida a Gilson Boschiero. Entre Rios/Guarapuava, Memorial Mathias e Elizabeth Leh, Cooperativa Agrária, 31 mai. 2013.

LEH, Karin K. Entrevista concedida a Gilson Boschiero. Entre Rios/Guarapuava, Memorial Mathias e Elizabeth Leh, 25 mai. 2013.

MYRDAL, Gunnar. Teoria Econômica e Regiões Subdesenvolvidas. Rio de Janeiro: Ed. Saga, 1982.

POULANTZAS, Nicos. As lutas políticas: o Estado, condensação de uma relação de forças. In: POULANTZAS, Nicos. O Estado, o poder e o socialismo. São Paulo: Graal, 2000.

PÜTSCH, Hans Jürgen. Prefeito há 6 anos de Rastatt ( $1^{\circ}$ mandato) Entrevista concedida a Gilson Boschiero, durante encerramento da Festa da Cevada. Distrito de Entre Rios às 12h00 do dia 13/10/2013.

OLIVEIRA, Anderson. L. de. Políticas públicas, urbanização e desenvolvimento regional endógeno - caso do Paraná. V Encontro de Economia Paranaense ECOPAR. Curitiba: Políticas Públicas, 2007.

RAFFESTIN, Claude. Por uma Geografia do Poder. Tradução de Maria Cecília França. São Paulo: Ed. Ática, 1993.

RATZEL, Friedrich. Politische Geographie. Osnabrück, Otto Zeller Verlag. 1974.

REDE SUL DE NOTÍCIAS. Agrária comemora 60 anos de conquistas nesta quintafeira. Guarapuava, 05 mai. 2011. Disponível em: <http://www.redesuldenoticias.com. br/noticia.aspx?id=35030 > . Acesso em 20 jun. 2013.

REDE SUL DE NOTÍCIAS. Peixada movimenta a programação da Festa da Cevada neste sábado. Guarapuava, 12 out. 2012. Disponível em: <http://www. redesuldenoticias.com.br/ noticia.aspx?id=46082 >. Acesso em: 16 jun. 2013.

REDE SUL DE NOTÍCIAS. Disponível em: <http://redesuldenoticias.com.br/noticia. aspx?id=588 27>. Acesso em: 30 out. 2013. 
SAQUET, Marcos A. As diferentes abordagens do território e a apreensão do movimento e da imaterialidade. Geosul. Florianópolis, v. 22, n. 43, pp. 55-76, jan./jun. 2007.

SAQUET, Marcos A. O território: diferentes interpretações na literatura italiana. In: SPOSITO, Eliseu S.; RIBAS, Alexandre D.; SAQUET, Marcos A. (Orgs.). Território e desenvolvimento: diferentes abordagens. Paraná: Unioeste, 2004, p. 139-140.

SAUSSURE, Ferdinand de. Curso de linguística geral. Cadernos Gestão Social, Salvador, v.2, n.1, p. 9-26, set./dez., 2009.

SAWAIA, Bader B. O Calor do Lugar: segregação e identidade. In: São Paulo em Perspectiva, vol. 9, n. 2. São Paulo: SEADE, abril/junho 1995.

SAWAIA, Bader B. O sofrimento ético-político como categoria de análise da dialética exclusão/inclusão. In: SAWAIA, Bader B. (Org.) As artimanhas da exclusão: análise psicossocial e ética da desigualdade social. Petrópolis: Vozes, 2001.

SILVESTRI FILHO, Cesar. Entrevista concedida a Gilson Boschiero. Guarapuava, Prefeitura de Guarapuava, 04 jun. 2013.

SOUZA, Marcelo J. L. de. O território: sobre espaço e poder. Autonomia e desenvolvimento. In: CASTRO, Iná. E. de; GOMES, Paulo C. da C.; CORRÊA, Roberto L. A. (Orgs.). Geografia: conceitos e temas. Rio de Janeiro: Bertrand Brasil, 2000.

STEIN, Marcos N. O Oitavo Dia: Produção de Sentidos Identitários na Colônia Entre Rios - PR (Segunda metade do século XX). Guarapuava/Paraná: Unicentro, 2011.

WANDERLEY, Mariângela B. Refletindo sobre a noção de exclusão. In: SAWAIA, Bader B. (Org.) As artimanhas da exclusão: análise psicossocial e ética da desigualdade social. Petrópolis: Vozes, 2001. 